\title{
STUDI PERBANDINGAN METODE WSM, WP DAN WASPAS DALAM PEMILIHAN GURU TERBAIK MENERAPKAN METODE EXPONENTIAL (STUDI KASUS: SMA NEGERI 1 TANJUNG PURA KABUPATEN LANGKAT)
}

\author{
Abdul Rasid Hasibuan \\ Prodi Teknik Informatika, STMIK Budi Darma, Medan, Indonesia \\ Email: abdulrasyidhasibuan17@gmail.com
}

\begin{abstract}
Abstrak
Selama ini pemilihan guru terbaik SMA Negeri 1 Tanjung Pura dilakukan setiap akhir tahun ajaran. Pemilihan guru tersebut di tujuan untuk memilih guru terbaik dan memotivasi guru-guru dalam hal melakukan pelajaran. Selama ini pemilihan guru terbaik di tanjung pura dilakukan dari beberapa cara seperti faktor kehadiran dalam mengajar, kerapian, menguasai materi kelas. Keadaan guru yang terpilih dipengaruhi faktor-faktor lain misalnya kedekatan, persahabatan, kekeluargaan. Sehingga guru yang terpilih tidak sesuai yang sebenarnya.Dalam pemilihan guru terbaik disekolah tingkat SMA/SMK dapat pemberian penghargaan terhadap prestasi dan dedikasi yang tinggi yang dicapai oleh guru dalam melaksanakan tugas propesionalnya sangat perlu diberikan, salah satunya yaitu dengan diselenggrakannya pemilihan guru terbaik di SMA/SMK.Dengan diselenggrakannya pemilihan guru terbaik di SMA Negeri 1 Tanjung Pura ini. Adanya pemilihan guru terbaik seharusnya dapat memotivasi guru untuk meningkatkan kinerja, disiplin, dedikasi, dan loyalitas untuk kepentingan masa depan bangsa dan negara.
\end{abstract}

Kata Kunci: Guru Berprestasi, Wsm, Wp, Waspas Dan Exponential, Spk

\begin{abstract}
So far, the selection of the best teachers at SMA Negeri 1 Tanjung Pura is conducted at the end of each school year. The selection of teachers is intended to choose the best teachers and motivate teachers in terms of doing the lesson. During this time the selection of the best teachers in Tanjung pura is done from several methods such as attendance in teaching, neatness, mastering classroom material. The situation of the chosen teacher is influenced by other factors such as closeness, friendship, family. So that the chosen teacher does not match the truth. In the selection of the best teachers in high school / vocational school level, the awarding of the high achievement and dedication achieved by teachers in carrying out their professional tasks needs to be given, one of which is the selection of the best teachers in high school / SMK. With the holding of the election of the best teacher in SMA Negeri 1 Tanjung Pura. The selection of the best teachers should be able to motivate teachers to improve performance, discipline, dedication, and loyalty for the future interests of the nation and state.
\end{abstract}

Keywords: Teacher Achievement, Wsm, Wp, Waspas and Exponential, Spk

\section{PENDAHULUAN}

Guru merupakan tonggak utama dalam dunia pendidikan, kemampuan dan prestasi siswa tidak lepas dari bagaimana peran seorang guru dalam mengajar dan membimbing siswa-siswanya. Berdasarkan Undang-undang Republik Indonesia No. 14 Tahun 2005 tentang Guru dan Dosen, pada Pasal 1 dijelaskan bahwa guru adalah pendidik profesional dengan tugas utama mendidik, mengajar, membimbing, mengarahkan, melatih, menilai, dan mengevaluasi peserta didik pada pendidikan anak usia dini jalur pendidikan formal, pendidikan dasar, dan pendidikan menengah.Sistem Pendukung Keputusan (SPK) merupakan salah satu bagian dari sistem informasi berbasis komputer yang interaktif dan berguna khususnya dalam pengambilan keputusan, penulis menggunakan SPK untuk pemilihan guru terbaik di SMA Negeri Tanjung Pura Kabupaten Langkat. Sistem ini digunakan untuk membantu pengambilan keputusan dalam situasi semi terstruktur dan situasi yang tidak terstruktur, dimana tak seorangpun tahu secara pasti bagaimana keputusan seharusnya dibuatGuru Berprestasi merupakan yang memiliki kinerja dan kompetensi, kepribadian sosial, dan profesional yang melampaui standar nasional. Menurut peneliti, Guru berprestasi adalah guru yang memiliki kemampuan atau kompetensi yang lebih unggul dibandingkan guru lain dan memiliki kinerja yang sangat baik sehingga mampu menyandang prestasi. Pemberian penghargaan terhadap prestasi dan dedikasi yang tinggi yang dicapai oleh guru dalam melaksanakan tugas propesionalnya sangat perlu diberikan, salah satunya yaitu dengan diselenggrakannya pemilihan guru berprestasi. Adanya pemilihan guru berprestasi seharusnya dapat memotivasi guru untuk meningkatkan kinerja, disiplin, dedikasi, dan loyalitas untuk kepentingan masa depan bangsa dan negara.

Selama ini pemilihan guru terbaik SMA Negeri 1 Tanjung Pura dilakukan pemilihan terbaik setiap akhir tahun ajaran. Pemilihan guru tersebut di tujuan untuk memilih guru terbaik dan memotivasi guru-guru dalam hal melakukan pelajaran. Selama ini pemilihan guru terbaik di tanjung pura dilakukan dari beberapa cara seperti faktor kehadiran dalam mengajar, kerapian, menguasai materi kelas. Keadaan guru yang terpilih dipengaruhi faktor-faktor lain misalnya kedakata, persahabatan, kekeluargaan. Sehingga guru yang terpilih tidak sesuai yang sebenarnya.

Menurut penelitian sebelumnya yang di lakukan oleh Suginam, Ermi Suryani Nasution, Sapria Ulandari Lubis, Mesran dalam jurnal yg berjudul Sistem Pendukung Keputusan Penerima Bantuan Siswa Miskin Menerapkan Metode WASPAS dan MOORA. Maka dapat disimpulkan bahwa metode WASPAS dapat diterapkan dalam sistem pendukung keputusan seleksi penerima bantuan siswa miskin, karena metode ini dapat memberikan rekomendasi prioritas penerima bantuan siswa miskin sesuai dengan kriteria penilaian yang digunakan dalam bentuk perankingan. Penerapan metode MOORA dapat untuk membantu dalam pemilihan penerima bantuan siswa miskin siswa dan hasil 
yang diberikan cukup efektif [1]. Menurut penelitian sebelumnya yang di lakukan oleh Yoga Handoko Agustin, Hendra Kurniawan dalam jurnal yg berjudul Sistem Pendukung Keputusan Penilaian Kinerja Dosen Menggunakan Metode Weighted Product (Studi Kasus: Stmik Pontianak). Maka dapat disimpulkan bahwa Menggunakan Metode Weighted Product (WP) proses penilaian kinerja dosen lebih efisian sehingga ketua program studi lebih cepat mendapatkan informasi tentang kinerja dosen [2].

\section{TEORITIS}

\subsection{Sistem Pendukung Keputusan}

Sistem Pendukung Keputusan (SPK) atau Decision Support System (DSS) adalah sebuah sistem yang mampu memberikan kemampuan pemecahan masalah maupun kemampuan pengkomunikasian untuk masalah dengan kondisi terstruktur dan tak terstruktur. Sistem ini digunakan untuk membantu pengambilan keputusan dalam situasiterstruktur dan situasi yang tidak terstruktur, dimana tak seorangpun tahu secara pasti bagaimana keputusan seharusnya dibuat.

\subsection{Guru}

Guru merupakan tonggak utama dalam dunia pendidikan, kemampuan dan prestasi siswa tidak lepas dari bagaimana peran seorang guru dalam mengajar dan membimbing siswa-siswanya. Berdasarkan Undang-undang Republik Indonesia No. 14 Tahun 2005 tentang Guru dan Dosen, pada Pasal 1 dijelaskan bahwa guru adalah pendidik profesional dengan tugas utama mendidik, mengajar, membimbing, mengarahkan, melatih, menilai, dan mengevaluasi peserta didik pada pendidikan anak usia dini jalur pendidikan formal, pendidikan dasar, dan pendidikan menengah.

\subsection{WSP, WP, WASPAS}

\subsubsection{Weighted Sum Model (WSM)}

Metode Weighted Sum Model (WSM) digunakan untuk mengetahui nilai potensi yang dimiliki oleh suatu alternatif dengan mempertimbangkan kriteria tertentu. Untuk menyelesaikan masalah MCDM salah satunya biasa menggunakan metode WSM. Bobot relatif dari kriteria dan nilai kinerja alternatif diperlukan dalam perhitungan metode WSM [3].

Rumus perhitungan metode WSM adalah :

$\mathrm{A}^{*}$ WSM-Score $=\frac{\max }{i} \sum \quad \frac{n}{j}=1$ aij $w j$, for $i=1,2,3, \ldots, m$

Keterangan:

$\mathrm{A}^{*}$ WSM-Score $=$ Skor WSM atau potensial skor

$a_{\mathrm{ij}}=\mathrm{i}$ adalah alternatif skor berdasarkan bobot relatif kriteria $\mathrm{j}$

$\mathrm{w}_{\mathrm{j}}=\mathrm{j}$ merupakan kriteria bobot relative

\subsubsection{Metode Weighted Product (WP)}

Menurut Sianturi Ingot Seen Metode Weighted Product (WP) merupakan salah satu metode yang digunakan untuk menyelesaikan masalah. Metode Weighted Product (WP) menggunakan perkalian untuk menghubungkan nilai atribut (kriteria), dimana nilai setiap atribut harus dipangkatkan dulu dengan bobot atribut (kriteria) yang bersangkutan [4].

Menurut Putra Jaya Metode Weighted Product memerlukan proses normalisasi karena metode ini mengaluhkan hasil penilaian setiap atribut. Hasil perkalian tersebut belum bermakna jika belum dibandingkan (dibagi) dengan nilai standart. Bobot untuk atribut manfaat berfungsi sebagai pangkat positif dalam proses perkalian, sementara bobot biaya berfungsi sebagai pangkat negatif. Metode Weighted Product menggunakan perkalian sebagai untung menghubungkan rating atribut, dimana rating setiap atribut harus dipangkatkan dulu dengan bobot yang bersangkutan. Proses ini sama halnya dengan proses normalisasi [5].

Dengan $\mathrm{i}=1,2, \ldots, \mathrm{m}$ dan $\mathrm{j}=1,2, \ldots \mathrm{n}$

Keterangan: $\Pi=$ product

$\mathrm{Si}=$ skor $/$ nilai dari setiap alternatif

$\mathrm{Xij}=$ nilai alternatif ke- $\mathrm{i}$ terhadap atribut ke- $\mathrm{j} w \mathrm{j}=$ bobot dari setiap atribut

Dimana $\sum \quad W^{j}=1_{(1)}$ adalah pangkat bernilai positif untuk atribut keuntungan dan bernilai negatif untuk atribut biaya. Untuk perangkingan / mencari alternatif yang terbaik dilakukan dengan rumus berikut:

\subsubsection{Weight Aggregated Sum Product Assesment (WASPAS)}

Weight Aggregated Sum Product Assesment (WASPAS) adalah metode yang dapat mengurangi kesalahankesalahan atau mengoptimalkan dalam penaksiran untuk pemililahan nilai tertinggi dan terendah. Demikian,Tujuan utama pendekatan MCDM adalah memilih opsi terbaik dari sekumpulan alternatif di hadapan berbagai kriteria yang saling bertentangan. Dalam tulisan ini, sebuah usaha dilakukan [2]. 
Untuk membenarkan ketepatan penerapan dan ketepatan pendekatan MCDM yang hampir baru, yaitu metode penilaian jumlah agregat berbobot (WASPAS).

Langkah proses perhitungan menerapkan metode WASPAS [2], yaitu:

1. Buat sebuah matriks keputusan $\mathrm{x}=[11 \times 12 . x 1 n \times 21 \times 11 . x 2 n \ldots . . x m 1 x m 1 . x m$

2. Melakukan normalisasi terhadap matrik $\mathrm{x}$

Kriteria Benefit

$\overline{x i j}=x i j m a X i x i j$

Kriteria Cost

$\overline{x i j}=\operatorname{minix} i j x i j$

3. Menghitung nilai Qi

$\mathrm{Qi}=0,5 \Sigma X i j w+0,5 \Pi(x i j) n j=1 w j n j=1$

Dimana :

Qi =Nilai dari Q ke i

Xijw $=$ Perkalian nilai Xij dengan bobot $(w)$

$0,5=$ Ketetapan

Alternatif yang terbaik merupakan alternatif yang memiliki nilai Qi tertinggi.

\section{ANALISA DAN PEMBAHASAN}

Tabel 1. Alternatif

\begin{tabular}{cc}
\hline Kode & Nama Alternatif \\
\hline A1 & Dra. Delta Simanjuntak \\
A2 & Drs. Sudirman Naibaho \\
A3 & Drs. Syaiful Fajar \\
A4 & Drs. Syafruddin \\
A5 & Parobahen Ginting S.Pd \\
A6 & M. Saleh S.Pd \\
A7 & Suzanna S.Pd \\
\hline
\end{tabular}

Kriteria-kriteria dan bobot yang telah ditetapkan oleh sekolah SMA Negeri 1 Tanjung Pura.

Tabel 2. Kriteria dan bobot

\begin{tabular}{ccc}
\hline Kode & Nama & Bobot \\
\hline C1 & Masa kerja (MK) & $20 \%$ Benefit \\
C2 & Pendidikan (P) & $20 \%$ Benefit \\
C3 & Prestasi Kinerja (PK) & $15 \%$ Benefit \\
C4 & Kepangkatan (K) & $15 \%$ Benefit \\
C5 & Disiplin (D) & $10 \%$ Benefit \\
C6 & Usia (U) & $10 \%$ Benefit \\
C7 & Jumlah Jam Mengajar (JJM) & $10 \%$ Benefit \\
\hline
\end{tabular}

\subsection{Metode Perbandingan Eksponensial (MPE)}

Dalam menghitung dan membandingkan proses pencarian dari tiga metode tersebut adalah sebagai berikut :

1. Menentukan alternatif

Untuk menganalisa perbandingan kecepatan antara metode WSM, WP, dan WASPAS dalam melakukan pencarian maka perlu dilakukan penentuan metode yang mana yang akan digunakan sebagai metode pencarian.

2. Menentukan kriteria

Untuk dapat mebandingkan alternatif maka selanjutnya perlu dilakukan penentuan kriteria dalam menganlisa proses dan cara kerjanya. Untuk kriterianya dapat dilihat pada tabel berikut :

Tabel 3. Penentuan Kriteria

\begin{tabular}{cc}
\hline Alternatif & Keterangan \\
\hline Metode WSM & Nilai potensi yang dimiliki oleh suatu alternatif \\
Metode WP & Perkalian untuk menghubungkan nilai atribut (kriteria) \\
Metode WASPAS & Metode untuk pemililahan nilai tertinggi dan terendah \\
\hline
\end{tabular}

3. Menentukan bobot kriteria 
Penentuan bobot merupakan salah satu komponen yang sangat berpengaruh terhadap nilai analisa, untuk itu menetepkan bobot kriteria berdasarkan tingkatan pengaruh dalam menentukan kecepatan dalam melakukan pencarian. Pembobotan kriteria dapat dilihat pada tabel dibawah ini :

Tabel 4. Pembobotan Masing-Masing Kriteria dari 3 metode

\begin{tabular}{lccl}
\hline \multicolumn{1}{c}{ Kriteria } & $\begin{array}{c}\text { Presentase } \\
\text { Pengaruh } \\
\text { Kriteria }\end{array}$ & $\begin{array}{c}\text { Bobot Range } \\
(0-1)\end{array}$ & \multicolumn{1}{c}{ Keterangan } \\
\hline Masa kerja & $70 \%$ & 20 & Masa kerja minimal 5 tahun \\
Pendidikan & $80 \%$ & 20 & $\begin{array}{l}\text { Pendidikan terakhir S1 } \\
\text { Dapat penghargaan dari kepala sekolah atau pemerintah } \\
\text { Prestasi kerja }\end{array}$ \\
daerah
\end{tabular}

4. Pemberian Nilai Pada Setiap Kriteria

Pada kriteria yang telah dibentuk harus diberikan nilai. Nilai tersebut dapat dilihat pada contoh dibawah ini yang dimana nilainya diambil berdasarkan analisa metode WSM, WP, dan WASPAS sebelumnya.

Tabel 5. Pemberian Nilai Terhadap Setiap Kriteria

\begin{tabular}{|c|c|c|c|c|}
\hline Alternatif & $\begin{array}{l}\text { Proses } \\
\text { Ke- }\end{array}$ & Alternatif & $\begin{array}{l}\text { Kriteria Guru } \\
\text { (KG) }\end{array}$ & $\begin{array}{l}\text { Jumlah } \\
\text { Rangking (JR) }\end{array}$ \\
\hline \multirow{8}{*}{$\begin{array}{l}\text { Metode } \\
\text { WSM }\end{array}$} & 1 & Dra. Delta & Masa kerja & 10.0933 \\
\hline & & Simanjuntak & & \\
\hline & 2 & $\begin{array}{l}\text { Drs. Sudirman } \\
\text { Naibaho }\end{array}$ & Pendidikan & 8.7395 \\
\hline & 3 & Drs. Syaiful Fajar & Prestasi kerja & 8.6159 \\
\hline & 4 & Drs. Syafruddin & Kepangkatan & 8.5342 \\
\hline & 5 & $\begin{array}{l}\text { Parobahen } \\
\text { Ginting S.Pd }\end{array}$ & Disiplin & 4.3497 \\
\hline & 6 & M. Saleh S.Pd & Usia & 4.9052 \\
\hline & 7 & Suzanna S.Pd & Jumlah Jam Mengajar & 8.3679 \\
\hline \multirow{7}{*}{$\begin{array}{l}\text { Metode } \\
\text { WP }\end{array}$} & 1 & Dra. Delta & Masa kerja & 7.825 \\
\hline & 2 & $\begin{array}{l}\text { Simanjuntak } \\
\text { Drs. Sudirman } \\
\text { Naibaho }\end{array}$ & Pendidikan & 7.620 \\
\hline & 3 & Drs. Syaiful Fajar & Prestasi kerja & 7.665 \\
\hline & 4 & Drs. Syafruddin & Kepangkatan & 7.330 \\
\hline & 5 & $\begin{array}{l}\text { Parobahen } \\
\text { Ginting S.Pd }\end{array}$ & Disiplin & 7.330 \\
\hline & 6 & M. Saleh S.Pd & Usia & 8.215 \\
\hline & 7 & Suzanna S.Pd & Jumlah Jam Mengajar & 8.270 \\
\hline \multirow{7}{*}{$\begin{array}{l}\text { Metode } \\
\text { WASPAS }\end{array}$} & 1 & Dra. Delta & Masa kerja & 33,05 \\
\hline & 2 & $\begin{array}{l}\text { Simanjuntak } \\
\text { Drs. Sudirman } \\
\text { Naibaho }\end{array}$ & Pendidikan & 36,85 \\
\hline & 3 & Drs. Syaiful Fajar & Prestasi kerja & 37,01 \\
\hline & 4 & Drs. Syafruddin & Kepangkatan & 33,05 \\
\hline & 5 & $\begin{array}{l}\text { Parobahen } \\
\text { Ginting S.Pd }\end{array}$ & Disiplin & 33,25 \\
\hline & 6 & M. Saleh S.Pd & Usia & 35,51 \\
\hline & 7 & Suzanna S.Pd & Jumlah Jam Mengajar & 33,25 \\
\hline
\end{tabular}


Setelah melakukan pengisian nilai terhadap masing-masing kriteria, maka proses berikutnya adalah malakukan perhitungan dengan menggunakan rumus dari Metode Perbandingan Eksponensial (MPE). Proses perhitungannya sebagai berikut :

Tabel 6. Perhitungan Analisa Perbandingan Dengan Menggunakan MPE

\begin{tabular}{|c|c|c|c|c|c|c|c|c|c|c|c|}
\hline \multirow{4}{*}{ No } & \multicolumn{8}{|c|}{ Kriteria } & \multirow{4}{*}{$\begin{array}{c}\text { Total } \\
\text { Nilai WP }\end{array}$} & \multirow{4}{*}{$\begin{array}{l}\text { Total } \\
\text { Nilai } \\
\text { WSM }\end{array}$} & \multirow{4}{*}{$\begin{array}{l}\text { Total Nilai } \\
\text { WASPAS }\end{array}$} \\
\hline & \multicolumn{4}{|c|}{ Jumlah Metode } & \multicolumn{4}{|c|}{ Hasil Perhitungan } & & & \\
\hline & \multirow[b]{2}{*}{$\mathrm{B}$} & WSM & WP & WASPAS & \multirow[b]{2}{*}{ B } & \multirow{2}{*}{$\frac{\mathrm{WSM}}{\mathrm{N}}$} & \multirow{2}{*}{$\frac{\mathrm{WP}}{\mathrm{N}}$} & \multirow{2}{*}{$\frac{\text { WASPAS }}{\mathrm{N}}$} & & & \\
\hline & & $\mathrm{N}$ & $\mathrm{N}$ & $\mathrm{N}$ & & & & & & & \\
\hline 1 & 20 & 10.0933 & 7.825 & 33,05 & 20 & 10.0933 & 7.825 & 33,05 & 2.4082 & 14,8154 & 4,8356 \\
\hline 2 & 20 & 8.7395 & 7.620 & 36,85 & 20 & 8.7395 & 7.620 & 36,85 & 13,5132 & 8,7322 & 7,8081 \\
\hline 3 & 15 & 8.6159 & 7.665 & 37,01 & 15 & 8.6159 & 7.665 & 37,01 & 20,1406 & 3,7042 & 4,7158 \\
\hline 4 & 15 & 8.5342 & 7.330 & 33,05 & 15 & 8.5342 & 7.330 & 33,05 & 18,5554 & 18,949 & 12,263 \\
\hline 5 & 10 & 4.3497 & 7.330 & 33,25 & 10 & 4.3497 & 7.330 & 33,25 & 76,6262 & 85,611 & 3,1098 \\
\hline 6 & 10 & 4.9052 & 8.215 & 35,51 & 10 & 4.9052 & 8.215 & 35,51 & 79,3232 & 62,456 & 3,5708 \\
\hline 7 & 10 & 8.3679 & 8.270 & 33,25 & 10 & 8.3679 & 8.270 & 33,25 & & 87,6 & 3,3032 \\
\hline & & & & & & & & Total & 330,3668 & 281,8968 & 39,6062 \\
\hline
\end{tabular}

Keterangan :

2. WP

: Bobot

3. WSM

: Metode Weight Product (WP)

4. WASPAS

: Metode Weighted Sum Model (WSM)

\section{(WASPAS)}

5. $\mathbf{N}$

: Nilai Kriteria

6. Total Nilai $: \sum(\mathrm{N})^{\mathrm{B}}$

Langkah-langkah / proses perhitungan adalah sebagai berikut :

1. Proses Perhitungan total nilai pada proses ke-1 :

$$
\begin{aligned}
\text { Nilai WP } & =(10,0933)^{20}+(10,0933)^{20} \\
& =1,2041+1,2041 \\
& =2,4082 \\
& =(7,825)^{20}+(7,825)^{20} \\
& =7,4077+7,4077 \\
& =14,8154 \\
\text { Nilai WSM } & =(33,05)^{20}+(33,05)^{20} \\
& =2,4178+2,4178 \\
& =4,8356
\end{aligned}
$$

2. Proses Perhitungan total nilai pada proses ke-2 :

$$
\begin{aligned}
\text { Nilai WP } & =(8,7395)^{20}+(8,7395)^{20} \\
& =6,7566+6,7566 \\
& =13,5132 \\
& =(7,620)^{20}+(7,620)^{20} \\
& =4,3561+4,3561 \\
& =8,7322 \\
\text { Nilai WASPAS } & =(33.85)^{20}+(33.85)^{20} \\
& =3,9009+3,9009 \\
& =7,8081
\end{aligned}
$$

3. Proses Perhitungan total nilai pada proses ke-3 :

$$
\begin{array}{ll}
\text { Nilai WP } & =(8,6159)^{15}+(8,6159)^{15} \\
& =10,0703+10,0703 \\
& =20,1406 \\
\text { Nilai WSM } & =(7,665)^{15}+(7,665)^{15} \\
& =1,8521+1,8521 \\
& =3,7042 \\
\text { Nilai WASPAS } & =(37,01)^{15}+(37,01)^{15} \\
& =2,3579+2,3579 \\
& =4,7158
\end{array}
$$

4. Proses Perhitungan total nilai pada proses ke-4

Nilai WP

$$
\begin{aligned}
& =(8,5342)^{15}+(8,5342)^{0,5} \\
& =9,2777+9,2777 \\
& =18,5554
\end{aligned}
$$




$$
\begin{aligned}
\text { Nilai WSM } & =(7,330)^{15}+(7,330)^{15} \\
& =9,4745+9,4745 \\
& =18,949 \\
\text { Nilai WASPAS } & =(33,05)^{15}+(33,05)^{15} \\
& =6,1315+6,1315 \\
& =12,263
\end{aligned}
$$

5. Proses Perhitungan total nilai pada proses ke-5 :

$$
\begin{aligned}
\text { Nilai WP } & =(4,3497)^{10}+(4,3497)^{10} \\
& =37,3131+37,3131 \\
& =74,6262 \\
\text { Nilai WSM } & =(7,330)^{10}+(7,330)^{10} \\
& =42,8055+42,8055 \\
& =85,611 \\
\text { Nilai WASPAS } & =(33,05)^{10}+(33,05)^{10} \\
& =1,5549+1,5549 \\
& =3,1098
\end{aligned}
$$

6. Proses Perhitungan total nilai pada proses ke-6 :

$$
\begin{aligned}
\text { Nilai WP } & =(4,9052)^{10}+(4,9052)^{10} \\
& =39,6616+39,6616 \\
& =79,3232 \\
\text { Nilai WSM } & =(8,215)^{10}+(8,215)^{10} \\
& =31,228+31,228 \\
& =62,456 \\
\text { Nilai WASPAS } & =(33.51)^{10}+(33.51)^{10} \\
& =1,7854+1,7854 \\
& =3,5708
\end{aligned}
$$

7. Proses Perhitungan total nilai pada proses ke-7 :

$$
\begin{array}{ll}
\text { Nilai WP } & =(8,3679)^{10}+(8,3679)^{10} \\
& =59,9+59,9 \\
& =119,8 \\
\text { Nilai WSM } & =(8,270)^{10}+(8,270)^{10} \\
& =43,8+43,8 \\
& =87,6 \\
\text { Nilai WASPAS } & =(33,25)^{10}+(33,25)^{10} \\
& =1,6516+1,6516 \\
& =3,3032
\end{array}
$$

Menghitung nilai prioritas keputusan

$$
\begin{array}{ll}
\text { Total Nilai WP } & =2,4082+13,5132+20,1406+18,5554+76,6262+79,3232+ \\
& 119,8 \\
= & 330,3668 \\
= & 14,8154+8,7322+3,7042+18,949+85,64+62,456+87,6 \\
= & 281,8968 \\
\text { Total Nilai WSM } & 4,8356+7,8081+4,7158+12,263+3,1098+3,5708+3,3032 \\
\text { Total Nilai WASPAS }= & 39,6062
\end{array}
$$

Menentukan Hasil Atau Prioritas Keputusan yaitu, Setelah diperoleh nilai akhir atau total nilai dari masing-masing alternatif, maka tahapan selanjutnya yang perlu dilakukan adalah menentukan prioritas keputusan berdasarkan nilai dari masing-masing alternatif. Hasil prioritas keputusan dapat dilihat pada tabel dibawah ini :

Tabel 7 Prioritas Keputusan

\begin{tabular}{lcc}
\hline \multicolumn{1}{c}{ Alternatif } & Total Nilai & Rangking \\
\hline Metode WSM & 330,3668 & 1 \\
Metode WP & 281,8968 & 2 \\
Metode WASPAS & 39,6062 & 3 \\
\hline
\end{tabular}

Pada tabel diatas menjelaskan bahwa alternatif yang memiliki total nilai terendah maka akan diposisikan pada rangking pertama hal ini dikarenakan semakin kecil total nilai yang diperoleh maka semakin sedikit jumlah usaha yang dilakukan oleh metode tersebut dalam melakukan pencarian. Berdasarkan analisa tersebut, maka metode WSM yang menjadi metode tercepat dalam melakukan proses pencarian.

\section{KESIMPULAN}


Berdasarkan hasil perancangan sistem yang dilakukan oleh penulis tentang studi perbandingan pemilihan guru terbaik SMA Negeri 1 Tanjung Pura, masih banyak kekurangan penulis dalam penyusunan skripsi ini. Dari babbab sebelumnya diambil suatu kesimpulan yang merupkan hasil akhir dari penulisan yaitu :

1. Perbandingan dapat diterapkan dari studi perbandingan metode WSM, WP, dan WASPAS dalam pemilihan guru terbaik.

2. Penerapan metode WSM, WP, dan WASPAS ini dilakukan dengan perbandingan kriteria dan sub kriteria terhadap masing-masing kriteria, kemudian menghitung normalisasi kriteria, dan untuk selanjutnya menghitung hasil perangkingan dari seluruh kriteria.

3. Perancangan studi perbandingan metode WSM, WP, dan WASPAS menerapkan aplikasi Microsoft Visual Studio 2008 dan database yang digunakan adalah Microsoft Access 2007, untuk alat bantu yang digunakan adalah UML yaitu berupa use case diagram, activity diagram.

\section{REFERENCES}

[1] E. S. N. S. U. L. M. Suginam, "Sistem Pendukung Keputusan Penerima Bantuan Siswa," Suginam, Ermi Suryani Nasution, Sapria Ulandari Lubis, Mesran, pp. Hal: 719 - 727, juli 2018.

[2] H. K. Yoga Handoko Agustin, "SISTEM PENDUKUNG KEPUTUSAN PENILAIAN KINERJA DOSEN," Yoga Handoko Agustin, Hendra Kurniawan, pp. 177-182, 2015.

[3] S. S. D. N. A. P. U. S. Mesran, "PENERAPAN WEIGHTED SUM MODEL (WSM) DALAM PENENTUAN PESERTA JAMINAN KESEHATAN MASYARAKAT," wsm (WEIGHTED SUM MODEL), vol. Volume (2), 1 Juli 2017.

[4] "Sianturi Ingot Seen," Metode Weighted Product (WP).

[5] "Putra Jaya," Metode Weighted Product. 